\title{
Persepsi Tenaga Kesehatan Terhadap Pentingnya Keberadaan Hospice Care Untuk Pasien Kanker Stadium Terminal di RSUP Fatmawati Jakarta.
}

\author{
${ }^{1}$ Okky Rachmad Ngakili, Moch. Prasetyo Mulyanto \\ ${ }^{1}$ Departemen Keperawatan Medikal Bedah STIKES Hang Tuah Surabaya \\ Email: ongakili@gmail.com,phone: 081939132391
}

\begin{abstract}
Hospice care is an integrated service that focused in giving full support to the patients for having enjoyable life and peaceful end of life. The research aimed to find medical professional's perception on the meaning, benefit and challenge on hospice care as well as multidisciplinary team roles in hospice care service for terminal illness patient in Fatmawati Central General Hospital, Jakarta. This Research utilized qualitative methodology with hermeneutic phenomenology approach. The participants were recruited through purposive sampling according to the inclusive criteria. A total number of 15 main participants consisted of 3 persons in each proffesion namely doctor, nurse, nutriciant, physiotherapist and pharmacist. A focus group discussion in the research and education room. The analyzed through N VIVO 11 program, interpreted within thematic and sub-theme analysis. The result showed that hospice care was very important. The health professionals stated that multidisciplinary team's roles in Hospice care acted as educator, consellor and care giver to respond to patients needs. It was concluded then that hospice care is important to improve patients quality of life in many aspects. The research recommended the hospice care to be implemented and supported by health care team and management of Fatmawati Central General Hospital Jakarta.
\end{abstract}

\section{Keyword: Perception, Medical Proffesional, Hospice Care.}

Abstrak: Hospice care merupakan pelayanan terpadu yangmemberikan dukungan kepada pasien supaya merasa hidup lebih nyaman dan damai diakhir kehidupan. Tujuan dari penelitian ini diketahuinya persepsi tenaga kesehatan mengenai makna, manfaat dan kendala hospice care, peranan tim multi disipliner di dalam hospice care untuk pasien kanker stadium terminal di RSUP Fatmawati Jakarta.Penelitian ini menggunakan metode kualitatif pendekatan fenomenologi hermeneutik. Partisipan dalam penelitian ini berjumlah 15 orang untuk partisipan utama masing-masing 3 orang dari setiap profesi yaitu; dokter, perawat, ahli gizi, fisioterapi dan farmasi. Teknik pengambilan sampel dengan cara purposive samplingsesuai dengan kriteria inklusi. Teknik pengumpulan data menggunakan teknik Focus Group Discussion untuk tenaga kesehatan yang dilaksanakan di Ruang Diklit RSUP Fatmawati Jakarta. Analisis data menggunakan N VIVO11 yang akan diinterpretasikan kedalam analisis tematik. Hasil penelitian menunjukkan bahwa hospice care sangat penting keberadaanya untuk pasien kanker stadium terminal karena dapat meningkatkan kenyamanan pasien, menjadikan pasien tetap merasa dihargai dan juga mendekatkan pasien dengan keluarga. Di dalam hospice care terdapat tim multidisipliner yang berperan sebagai educator, konseling dan sebagai care giver dalam pemenuhan kebutuhan pasien. Kendala hospice care belum dilaksanakan salah satunya adalah belum adanya ruangan khusus untuk mendirikan hospice care sesuai standar yamg telah ditentukan. Simpulan dari penelitian ini adalah hospice care penting dilakukan karena dapat meningkatkan kualitas hidup pasien baik secara biologis, psikologis, sosiologis, spiritual dan kultural. Saran dalam penelitian ini untuk tenaga kesehatan dan manajemen RSUP Fatmawati Jakarta agar mendukung serta memfasilitasi program pengembangan hospice care, didukung kesiapan tim multidisipliner dan 
kelengkapan fasilitas yang dimiliki RSUP Fatmawati serta memberikan edukasi dan rekomendasi terhadap perawatan pasien kanker stadium terminal.

Kata Kunci: Persepsi, Tenaga kesehatan, Hospice care

\section{Pendahuluan}

Kanker masih menjadi bayangan hitam bagi masyarakat di dunia, karena merupakan masalah kesehatan yang belum ada pengobatan secara pasti, tetapi kanker dapat dicegah. Kanker menjadi penyebab kematian nomor 2 di dunia sebesar $13 \%$ setelah penyakit kardiovaskuler (WHO, 2013). Di Indonesia, prevalensi penyakit kanker juga cukup tinggi. Pada tahun 2008 penderita kanker yang meninggal dunia sebanyak 7,6 juta orang dari 12,7 juta kasus. Pada tahun 2012 penderita kanker menjadi 14,1 juta kasus dan yang meninggal 8,2 juta. Hal ini berarti ada peningkatan sebanyak 600.000 orang yang meninggal setiap 4 tahun akibat kanker. Maka dapat diperkirakan pada tahun 2016 penderita kanker yang meninggal dunia sebanyak 10, 6 juta orang. Diperkirakanjuga pada tahun 2030, insiden kanker dapat mencapai 26 juta orang dan yang meninggal 17 juta orang (DepKes RI, 2015). Berdasarkan data riset kesehatan dasar (RisKesDas) tahun 2013, prevalensi tumor/kanker di Indonesia adalah 1,4 per 1000 penduduk atau sekitar 330.000 orang.

Penderita kanker yang mengalami komplikasi berkelanjutan dan sudah termasuk dalam grade (stadium) IV/terminal akan rentan terhadap pengobatan dan selanjutnya pasien akan diklasifikasikan dalam grade $\mathrm{X}$ karena sudah tidak dapat dinilai lagi tingkat keganasan dari sel kanker (Lewis, 2011). Pada tahap kanker stadium IV/terminal ini penderita akan menghadapi situasi di akhir kehidupan (End Of Life) yang memerlukan banyakkeputusan dalam pemberian layanannya (End Of Life Care: EOLC) dimana situasi tersebut dapat mempengaruhi lebih jauh terhadap kualitas hidup pasien.
Rulland dan Moore (2001) mengusulkan tentang "Peacefull End Of Life" dimana diterapkan tentang 5 prinsip yaitu; 1) bebas dari rasa nyeri 2) mengalami kenyamanan 3) merasa tetap terhormat dan sejahtera 4) merasa tetap damai meskipun dalam keadaan sakit dan 5) tetap merasa dekat kepada orang lain dan mereka yang peduli (Mellanie, 2011; Alligood, 2014). Kelima hal tersebut dapat diterapkan dalam asuhan keperawatan khususnya bagi mereka yang mendekati akhir kehidupan (EOLC: End of Life Care) seperti dengan mendirikan program hospice care (Mellanie, 2011; Alligood, 2014).

Prinsip tentang hospice care yaitu memberikan perawatan suportif kepada orang-orang ditahap akhir penyakit terminal dan fokus pada kenyamanan dan kualitas hidup, bukan pada penyembuhan (Connor, 2009).Di Indonesia penatalaksanaan hospice care masih belum terfokus, karena masih banyak dikaitkan bahwa antara palliative care, hospice care dan homecare adalah sama dan masih belum adanya rumah sakit di Indonesia yang menyediakan program perawatan hospice care yang dilakukan di Rumah Sakit.

Studi awal yang dilakukan di RSUP Fatmawati Jakarta pada hari senin tanggal 20 Juli 2016 salah satu persepsi dari tim kesehatan yaitu perawat, mengatakan bahwa "Hospice care penting dilaksanakan karena hospice care dapat memberikan pelayanan terpadu untuk pasien kanker stadium terminal sehingga dapat meningkatkan kualitas hidup pasien dan dapat memberikan pengertian kepada keluarga pasien untuk menerima proses dari kehidupan pasien", maka keberadaan hospice care untuk pasien kanker stadium terminal sangat dibutuhkan. 
Hal ini mendorong peneliti untuk menggali pentingnya keberadaan hospice care di Rumah Sakit besar salah satunya RSUP Fatmawati Jakarta yang belum diketahui apakah sudah atau belum mencanangkan program hospice care pada pasien kanker stadium terminal.

\section{Metode Penelitian}

Pada penelitian ini menggunakan metode kualitatif dengan pendekatan fenomenologi hermeunetik. Peneliti melakukan secara FGD (Focus Group Discussion) untuk partisipan utama yang dilakukan pada penelitian ini menggunakan metode kualitatif dengan pendekatan fenomenologi hermeunetik. Peneliti melakukan secara FGD (Focus Group Discussion) untuk partisipan utama yang dilakukan pada tanggal 19 Juli 2016 sebanyak 7 orang dan 28 Juli 2016 sebanyak 8 orang dan FGD dilakukan pada pukul 13.00 - 17.00 WIB di Ruang Diklit RSUP Fatmawati Jakarta.

\section{Hasil Penelitian dan Pembahasan}

Berdasarkan hasil analisa data menggunakan N VIVO 11 didapatkan 3 tema jika dilihat berdasarkan persepsi tenaga kesehatan yaitu: 1). Makna Hospice Care, 2). Penatalaksanaan Hospice Care dan 3). Peranan Hospice Care. Dimana dalam analisa data akan mengarah terhadap setiap pertanyaan yang dijadikan sebagai acuan FGD dan berdasarkan sub tema yang telah ditemukan sesuai dan menggunakan analisa data dengan $\mathrm{N}$ VIVO 11 antara lain:

\section{Persepsi Tenaga Kesehatan Terhadap Makna Dari Hospice Care}

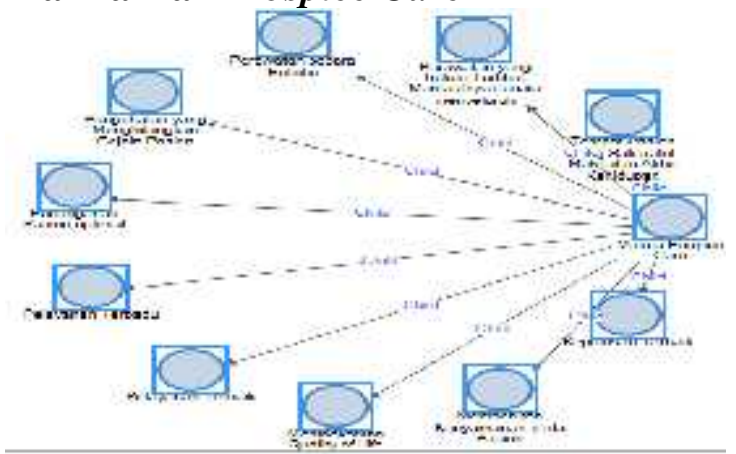

Gambar 1 Skema Model Tema Dalam Penelitian. Sumber: Data Primer Hasil Olah Data NVivo versi 11.0

Para partisipan yaitu tenaga kesehatan telah memberikan gagasan tentang makna Hospice Care.Terdapat 10 subtema yang dihasilkan dari berbagai persepsi tenaga kesehatan. Sub tema pertama adalah "Pelayanan Terpadu". Tenaga kesehatan yang memberikan persepsi bahwa Hospice Care merupakan pelayanan terpadu adalah Partisipan dari Ahli Gizi 1 (PA1), Perawat 1 (PP1), Fisioterapis 1(PF1) dan Fisioterapis 2 (PF2). Ke 4 partisipan tersebut mengatakan bahwa Hospice Care merupakan pelayanan terpadu yang didalamnya terdapat tim multidisipliner dan keluarga yang difokuskan kepada pasien kanker stadium terminal sehingga dapat memenuhi kebutuhan secara bio, psiko, sosio, spiritual dan kultural serta perawatan hospice care dilakukan selama 24 jam/hari.

Pendapat dari partisipan selanjutnya yaitu dari perawat 3 (PP3) yang mengatakan "Perawatan holistic yang dilakukan di Rumah Sakit dan hampir sama dengan home care". PD3 yang mengatakan " hospice Care dan Paliative care berbeda. Jika hospice Care pengobatan hanya ditujukan untuk menghilangkan gejala pasien sedangkan paliative care tetap diberikan treatment medical".

Berdasarkan pendapat para tenaga kesehatan diatas dapat disimpulkan hospice care adalah pelayanan terpadu yang difokuskan pada pasien kanker stadium terminal yang didalamnya terdapat tim multidisipliner dan keluarga yang dapat memberikan perawatan secara holistic, sehingga pasien akan merasa tenang dan damai meskipun diakhir kehidupan.

Sub tema selanjutnya yang berdasarkan tentang persepsi tenaga kesehatan terhadap makna hospice care adalah Tempat untuk pasien yang sakaratul maut atau akhir kehidupan. 
Jumlah tenaga kesehatan yang mengatakan tema tersebut sebanyak 2 partisipan yaitu: 1) partisipan dari ahli Gizi 2 (PA2) dan Fisioterapis 3 (PF3).

Pendapat dari Ahli Gizi 2 (PA2) mengatakan "Hospice Care merupakan tempat untuk pasien yang sakaratul maut yang membutuhkan dukungan keluarga".Hal ini terlihat bahwa tema ke 2 dari pendapat tenaga kesehatan tentang makna hospice care adalah tempat pasien untuk sakaratul maut.

Subtema selanjutnya adalah "Meningkatkan Quality of Life".Jumlah partisipan yang mengatakan hal tersebut sebanyak 1 partisipan yaitu Ahli Gizi 1 (PA1) yang mengatakan "Manfaat hospice care dapat meningkatkan Quality of Life pasien sehingga pasien merasa dihargai meskipun saat sakit".

Berdasarkan dari beberapa subtema diatas tentang manfaat hospice care dapat disimpulkan hospice care memiliki maanfaat antara lain:

1. Memberikan kenyamanan pasien

2. Memberikan pelayanan terbaik untuk pasien dan keluarga serta Rumah Sakit.

3. Meningkatkan Quality of Life.

Dari partisipan diatas mengutarakan hal yang sama tentang penanganan pasien.
Seperti yang diungkapkan oleh Dokter 3 (PD3) mengatakan bahwa "Hospice care penting diadakan untuk pasien kanker stadium terminal karena penanganan pasien kanker stadium terminal adalah hal yang khusus dan delicate untuk diperhatikan, apabila ada kondisi yang menunjang dan memberikan kenyaman serta manfaat besar, maka perlu dilakukan". Sedangkan menurut Fisioterapi 1 (PF1) mengatakan bahwa "Hospice care penting diadakan untuk pasien kanker stadium terminal namun saat melakukan penanganan pasien harus memperhatikan kondisi dan juga anjuran dan penilaian secara medis kepada pihak keluarga, dimana pihak keluarga adalah kunci dari pelaksanaan ini”.

Dari hasil pendapat beberapa tenaga kesehatan dapat disimpulkan bahwa hospice penting diadakan untuk pasien kanker stadium terminal karena merupakan keputusan terbaik dalam penanganan pasien.

Hal ini menunjukkan salah satu manfaat dari hospice care dapat meningkatkan kualitas hidup pada pasien kanker stadium terminal.

\section{Persepsi Tenaga Kesehatan Terhadap Penatalaksanaan Hospice Care}

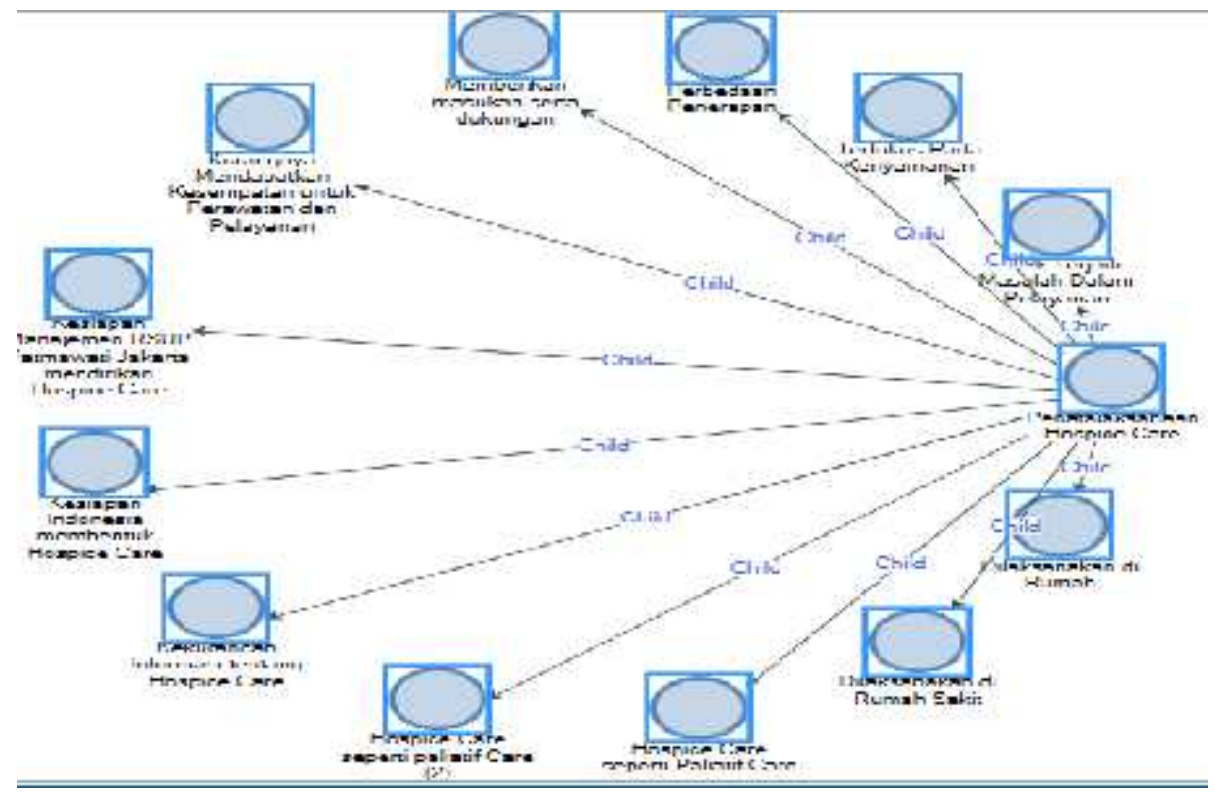

Gambar 2 Skema Model Tema "Penatalaksanaan Hospice Care" Dalam Penelitian. Sumber: Data Primer Hasil Olah Data NVivo versi 11.0 
Berdasarkan dari hasil analisa data menggunakan N VIVO 11 dapat diperoleh hasil jumlah sub tema yang dihasilkan oleh penatalaksanaan hospice care sebanyak 11 sub tema.

Subtema pertama adalah "Kurangnya Mendapatkan Kesempatan Untuk Perawatan dan Pelayanan". Jumlah partisipan yang mengatakan hal tersebut sebanyak 9 partisipan antara lain: 1). Ahli Gizi 1 (PA1), 2). Ahli Gizi 2 (PA2), 3).Dokter 1 (PD1), 4).Farmasi 1 (PM1), 5) Farmasi 2 (PM2), 6).Farmasi 3 (PM3), 7).Fisioterapist 1 (PF1), 8).Fisioterapist 2 (PF2) dan 9).Fisioterapist 3 (PF3).

Menurut Ahli Gizi 1 (PA1) mengatakan bahwa "Pasien dan keluarga pasien tidak mendapatkan opsi untuk perawatan dan pelayanan yang seharusnya bisa mereka dapatkan".Pendapat partisipan selanjutnya yaitu Ahli Gizi 2 (PA2) tentang tema tersebut adalah "keadaan damai dimana pasien bisa mendapatkan dan diperhatikan sampai akhir hayatnya menjadi sebuah pilihan yang belum bisa didapatkan".

Pendapat Dokter 1 (PD1) mengatakan bahwa "Kesempatan rumah sakit dan pelayanan kesehatan lainnya untuk memilki layanan dan fasiitas ini belum terpenuhi, sebuah kesempatan yang seharusnya bisa dilihat dan ditilik opportunitinya". Partisipan selanjutnya memiliki pendapat yang hampir sama dengan yang telah diurtarakan oleh ke tiga dari partisipan tersebut.

Hal ini bisa menjadi salah satu kendala, kenapa hospice care belum didirikan. Dari beberapa pendapat partisipan ada 2 partisipan yang memiliki pendapat yang hampir sama yaitu pendapat dari Ahli Gizi 3 (PA3) dan pendapat dari Dokter 3 (PD3). Ahli Gizi 3 mengatakan bahwa "Kekurangan informasi dan juga kesempatan agar pasien bisa mendapatkan pelayanan yang maksimal". Hal ini diakibatkan karena hospice care belum dilaksanakan di Rumah Sakit.
Pendapat Dokter 3 (PD3) mengatakan bahwa "Pasien dan keluarga kekurangan dan kehilangan informasi dan layanan yang mereka butuhkan".Berdasarkan dari beberapa pendapat berarti dampak belum diselenggarakannya Hospice Care sangat signifikan karena menurut para tenaga medis salah satu dampaknya adalah kurangnya informasi terhadap kesehatan khususnya informasi hospice care.

Semua partisipan utama baik dari profesi Dokter, Perawat, Ahli Gizi, Fisioterapi dan Farmasi memiliki persepsi yang sama yaitu Tim multidisipliner. Tetapi ada partisipan dari Dokter 2 (PD2) yang berpendapat selain Tim multidisipliner dalam hospice care, Keluarga harus berperan dalam hospice care. Seperti yang diungkapkan oleh Dokter 2 (PD2) bahwa "Semua pihak terkait dalam paliative care dan hospice care tentunya baik di Rumah sakit maupun dilokasi lainnya, keluarga memegang peranan penting dalam hal ini untuk menentukan dan mendiskusikan dengan dokter dan lainnya".

\section{Persepsi Tenaga Kesehatan Terhadap Peranan Tim Multidisipliner Dalam Hospice Care}

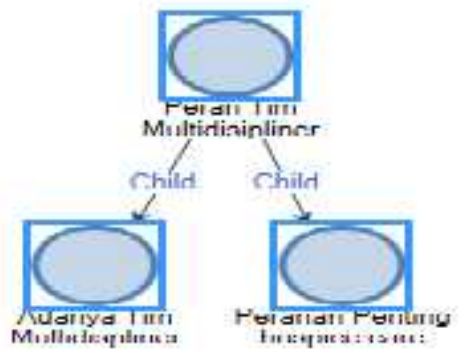

$\begin{array}{rrr}\text { Gambar } 3 & \text { Skema Model Tema "Peranan } \\ \text { Tim Multidisipliner } & \text { Dalam } \\ \text { Hospice Care" } & \text { Dalam } \\ \text { Penelitian. Sumber: } & \text { Data } \\ & \text { Primer Hasil Olah } & \text { Data } \\ & \text { NVivo versi } 11.0 & \end{array}$

Seluruh partisipan utama setuju bahwa peran Tim multidisipliner dalam hospice care sangat penting.Ke tiga partisipan dari Ahli Gizi berpendapat bahwa dalam hospice careakan mengatur koordinasi 
terkait kebutuhan gizi pasien kanker, karena menurut tim ahli gizi dengan pengaturan diit pasien akan merasa diberikan pelayanan yang maksimal.

Menurut Ahli Gizi 2 (PA2) mengatakan " Tim multidisipliner dalam hospice care sangat penting peranannya yaitu seperti ahligizi yang harus berkoordinasi terhadap semua pihak akan kebutuhan pasien khususnya pada gizi pasien".

Pendapat dari ketiga partisipan dari perawatpun sama yaitu Tim multidisipliner dalam hospice care memiliki peran sangat penting. Peran perawat dalam hospice care menurut perawat 1 (PP1) sebagai educator dan bimbingan konseling terhadap pasien dan keluarga serta dapat memberikan penjelasan tentang teknik nyeri nonfarmakologis. Sedangkan menurut perawat 2 (PP2) berpendapat bahwa " Peran yang lengkap dan harus saling melengkapi dan mendukung segala penatalaksanaan hospice care".

Pendapat selanjutnya dari tenaga kesehatan yang berasal dari dokter tentang Tim multidisipliner dalam hospice care juga sama yaitu semua penting.

Menurut pendapat dari Dokter 1 (PD1) perannan dokter didalam hospice care sebagai leader untuk mengarahkan setiap intervensi yang akan dilakukan didalam hospice care. Dokter 1 (PD1) mengatakan "Tim multidisipliner menentukan dan memegang peran yang penting, tidak bisa dipisahkan dan berdiri sendiri, keluarga juga menentukan arah dan keinginan dari pasien".

Partisipan selanjutnya adalah dari profesi Farmasi. Ke tiga partisipan dari profesi farmasi tersebut juga memiliki pendapat yang sama yaitu peran tim multidisipliner dalam hospice care sangat penting. Menurut pendapat dari Farmasi 3 (PM3) peranan farmasi dalam hospice care adalah untuk mengatur dan berkoordinasi dengan dokter dan tenaga kesehatan lainnya tentang kandungan obat yang diberikan pada pasien. Sedangkan menurut Farmasi 2 (PM2) mengatakan bahwa "Tim multidisipliner dalam hospice care harus memiliki peran yang maksimal, maksudnya kondisi dan koordinasi harus dibicarakan dan direncanakan".

Partisipan utama yang terakhir adalah profesi fisioterapi. Ke tiga partisipan tersebut juga berpendapat yang sama bahwa peran tim multidisipliner di dalam hospice care sangat penting. Menurut pendapat dari Fisioterapi 2 (PF2) mengatakan bahwa "Semua pihak yang terkait dalam system kesehatan harus diperhatikan, direncanakan dan dijelaskan secar seksama, dan peran serta harus sesuai". Menurut Fisioterapi 1 (PF1) peranan fisioterapi dalam hospice care adalah melatih pergerakan baik pasien bed rest total maupun tidak.

Berdasarkan dari pendapat beberapa partisipan diatas dapat disimpulkan bahwa peran tim multidisipliner dalam hospice care sangat penting dan Peraturan dalam hospice care juga perlu dimengerti serta adanya SOP yang jelas dalam mengatur peran serta wewenang dari setiap bidang keilmuan.

\section{Persamaan Ungkapan Partisipan Utama}

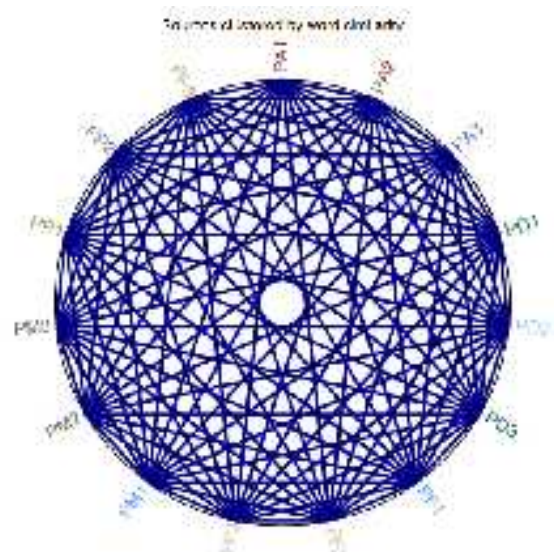

Gambar 4.9 Kesamaan Ungka

pan Partisipan Utama 1-15. Sumber: Data Primer Hasil Olah Data NVivo versi 11.0

Berdasarkan diagram diatas pada partisipan 1 sampai 15 didapatkan kesamaan ungkapan ditandai dengan 
masing-masing partisipan terdapat hubungan garis dari pada partisipan yang satu dan yang lainnya. Didapattkan juga pada partisipan PD3 dan PD1 memiliki kesamaan yang paling tinggi dengan nilai 0.8371 selanjutnya partisipan PM1 dan PF1 dengan nilai koefisien 0.8316 .

Salah satu kesamaan ungkapan yang di sampaikan PD 3 yaitu PD3 "Hospice Care dan Paliatif Care berbeda. Jika hospice care pengobatan hanya ditujukan untuk menghilangkan gejala pasien sedangkan paliatif care tetap diberikan treatment medical".

PD1: PD1 "Hospice Care memiliki peranan penting dalam program pelayanan kesehatan karena salah satu manfaat hospice care adalah untuk tetap memberikan kenyamanan pasien meskipun dalam keadaan akhir hayat".

\section{A. Simpulan dan Saran}

Simpulan

1. Persepsi Tenaga Kesehatan dan Pasien Persepsi tenaga kesehatan dan pasien terhadap pentingnya keberadaan hospice care untuk pasien kanker stadium terminal di RSUP Fatmawati Jakarta sangatlah penting. Hospice care secara konsep sangat nyata jika diterapkan di RSUP Fatmawati. Dengan adanya keberadaan hospice care memberikan pelayanan terpadu dengan tim multidisipliner yaitu dokter, perawat, ahli gizi, farmasi dan fisioterapi serta keluarga pasien yang dapat memberikan pelayanan 24 jam

2. Perencanaan Bentuk Hospice Care di RSUP Fatmawati Jakarta

Menurut tenaga kesehatan dari RSUP Fatmawati Jakarta bentuk Hospice Care yang dapat diterapkan di RSUP Fatmawati Jakarta adalah "Hospice Care in Hospital Setting" sebagai permulaan memulai hospice care. Rumah Sakit tetap memperhatikan standart penata ruangan hospice care di Rumah Sakit. Dengan keberadaan hospice care dapat diberikan perawatan di akhir kehidupan atau sering dikenal dengan EOLC (End of Life Care).

3. Peranan Tim Multidisipliner Dalam Hospice Care

Dalam hospice care terdapat peranan masing-masing dari tim mutidisipliner antara lain: 1) Peranan perawat yaitu berperan sebagai advokasi dan yang utama adalah memberikan pendidikan kesehatan untuk pasien dan keluarga dalam manajemen perawatan, manajemen rasa nyeri dan juga dalam menghilangkan gejala pasien. 2). Peranan dokter spesialis kanker yaitu sebagai direktur medis dalam pengaturan tim multidisipliner hospice care, menegakkan diagnosa awal dan diagnosa berkelanjutan 3). Peranan farmasi yaitu sebagai pakar dalam peracikan pengobatan yang efektif sehingga dapat mencapai target untuk terapi menghilangkan gejala pasien. 4). Peranan fisioterapi yaitu memberikan suatu pergerakan dengan tetap mempertahankan batas maksimum pasien (kenyamanan pasien), melatih pergerakan pasien dalam batas kemampuan. 5). Peranan ahli gizi adalah Sebagai pendukung untuk menilai pasien dengan kebutuhan gizi pasien.

4. Model Keperawatan Hospice Care Yang Dapat Diterapkan di RSUP Fatmawati Jakarta

Tenaga kesehatan sangat setuju jika model konsep keperawatan dari Rulland and Moore diterapkan dalam hospice care. Model keperawatan Rulland and Moore sudah mencakup semua kualifikasi yang dibutuhkan pasien kanker stadium terminal yaitu bebas dari rasa nyeri, memberikan kenyamanan pasien, menjadikan pasien tetap sejahtera, menjadikan pasien tetap damai diakhir kehidupan dan mendekatkan pasien kepada orangorang terdekat. 


\section{Saran}

1. Manajemen RSUP Fatmawati Jakarta

a. Manajemen RSUP Fatmawati Jakarta supaya memperhatikan pengembangan pelayanan hospice care, karena pelayanan hospice care sebagai salah satu bentuk meningkatkan kualitas rumah sakit yang bertaraf internasional dan menjadi acuan pelaksanaan kesehatan bagi Rumah Sakit lain di Indonesia.

b. Manajemen RSUP Fatmawati Jakarta supaya memfasilitasi sarana dan prasarana sesuai dengan standart mendirikan hospice care, karena program hospice care harus mengacu pada kebutuhan pasien dan standart yang telah ditentukan secara internasional.

2. Komite Pengembangan dan Penelitian di RSUP Fatmawati Jakarta

a. Komite Pengembangan dan Penelitian di RSUP Fatmawati Jakarta supaya membantu mengembangkan dan mensosialisasikan hasil penelitian dari keberadaan hospice care baik untuk tenaga kesehatan, pasien dan keluarga pasien.

b. Komite Pengembangan dan Penelitian di RSUP Fatmawati Jakarta supaya mendukung serta memfasilitasi program pengembangan hospice care.

3. Tenaga Kesehatan di RSUP Fatmawati Jakarta

a. Tenaga Kesehatan di RSUP Fatmawati Jakarta supaya memberikan edukasi dan rekomendasi terhadap perawatan pasien kanker stadium terminal.

b. Tenaga Kesehatan di RSUP Fatmawati Jakarta supaya lebih memperhatikan kebutuhan pasien baik secara bio, psiko, sosio, spiritual dan kultural khususnya pada pasien dengan kanker stadium terminal.
4. Peneliti selanjutnya.

a. Jika hasil dalam penelitian ini sudah diterapkan, maka peneliti selanjutnya supaya memperhatikan perkembangan kualitas hidup pasien kanker stadium terminal dan tatalaksana perawatan kesehatan baik tim medis maupun operasional apakah sudah sesuai standart hospice care atau belum sesuai standart.

b. Membantu mempublikasikan pelayanan hospice care sebagai salah satu alternative perawatan kesehatan yang dapat diterapkan model konsep Rulland and Moore.

\section{Daftar Pustaka}

Afiyanti. (2014). Metodologi Penelitian kualitatif Dalam Riset Keperawatan. Rajawali. Jakarta.

Alligood. (2014). Nursing theorist and their works. St.Louis: Elsevier Mosby

American Cancer Society. (2014). Information and Resources for Cancer. www.cancer.org

Bandur. (2014). Penelitian kualitatif Metodologi, Desain \& Teknik Analisis Data Dengan NVIVO 10. Mitra Wacana Media. Jakarta.

Black \& Hawks. (2009). Medical-surgical nursing: Clinical management for positive outcome (7th ed.). St. Louis: Elsevier Saunders.

Boyd. (2016). Nurses' Perceptions and Experiences With End-of-Life Communication and Care. Journal of California State University. Fullerton. Vol. 38, No. 3.

Bray. (2013). Patient and family perceptions of hospice services: 'I knew they weren't like hospitals'. Original Scientific Paper: Qualitative Research. Journal of Department of General Practice and Primary Health Care. The University of Auckland. New Zealand

Brooks. (2013). Improving Access: Identifying the Top Four Barriers to Hospice Admission. Halcyon Hospice. USA

Brunner \& Suddarth. (2010). Textbook Medical Surgical Nursing Brunner\&Suddarth (ed 13th). China: Lisa McAllister

Carlson. (2010). Mindfulness for Cancer and Terminal Illness. Calgary Alberta. Canada

Center for Medicare services. (2014). Center for medicare \& Medicaid services. www.cms.gov

Charmaz. (2009). Constructing grounded Theory: A practical guide Through Qualitative 
Analysis. Thousand Oaks: Sage

Publication Ltd.

Connor. (2009). Hospice and Palliative Care. Oxford University Press: New York

Creswell. (2013). Qualitative inquiry \& research design: Choosing among five approaches. Thousand Oaks: Sage Publication Ltd.

Daniela. (2013). Hospice Care In A Hospital Setting: The Experience Of A Multidisciplinary Team. Original artikel: Text Context Nursing, Florianopolis, 2013 Out-Dez; 22(4): 1134-41.

DepKesRI. (2014). Publikasi Data Dan Informasi. www.depkes.go.id

DepKesRI. (2015). Publikasi Data Dan Informasi. www.depkes.go.id

Desen, W. (2008). Onkologi Klinis Edisi 2. Beijing Cina: Science Publication

DeWitt \& Kumagai. (2012). Medical-surgical nursing concepts and practice. Philadelphia: Elsevier Mosby.

Doddy Owen. (2012). Final-year student nurses' perceptions of role transition. British Journal of Nursing. Vol.21,No.11. Department of Nursing and Midwifery. University of Limerick.

Field. (2012). Palliative And Hospice Care Ethics. Oxford University Press: New York

Finley. (2009). Methodology Of Research Qualitative. Oxford University Press: New York

Harwell. (2012). Research design: Qualitative, quantitative, and mixed methods. In $C$. Conrad \& R.C. Serlin (Eds.). The Sage handbook for research in education: Pursuing ideas as the keystone of exemplary inquiry (Second Edition). Thousand Oaks, CA: Sage.

Heberth. (2011). The Nurse Advocate in End of Life Care. The Ochsner Journal 325-329.

Heydarnejad et al. (2009). Factors Affecting Quality of Life in Cancer Patients Undergoing Chemotherapy, (online), (http://www.ncbi.nlm.nih.gov /pmc/articles/PMC3158510/pdf /AFHS1102-0266.pdf, diakses 17 Februari 2012).

ICSI. (2013). Health Care Guideline Palliative Care for Adults. Institute for Clinical System Improvement: USA.

Ignatavicius \& Workman. (2010). Medical surgical nursing: Patient centered collaborative care. St. Louis: Elsevier Saunder.

Infeld. (2013). Hospice Care and Cultural Diversity. The Haworth Press. New York

Institute for Clinical System Improvement. (2013). Health Care Guidelines. Olmsted Medical Center. Philadelphia. www.icsi.org
Karen Hess. (2008). The Family Handbook of Hospice Care. Fairview Press Minneapolis: USA

Kathryn. (2010). The Role of the Pharmacist in Hospice Care. Wellness Partner Free CE. the Accreditation Council for Pharmacy Education as a provider of continuing pharmacy education. United State

Kindi. (2012). Pattern of Hospitalization of Patients With Cancer in an Acute Palliative Care Setting: Qatar's Experience. American Journal of Hospice and palliative Medicine. AM J HOSP PALLIAT CARE 30:25.

Kirk. (2014). Hospice Ethics Policy and Practice in Palliative Care. Oxford University Press. New York

Lewis. (2011). Medical Surgical Nursing. Assesment and Managemnet of Clinical Problems (ed 8). st. Louis: Elsevier

Lindley. (2012). Trends in services Among Pediatric Hospice Providers During 2002 to 2008. American Journal of Hospice and Palliative Medicine. AM J HOSP PALLIAT CARE 30:68.

Manuaba. (2008). Masalah Penanganan Kanker di Indonesia. Orasi Ilmiah: Pidato Pengukuhan Jabatan Guru Besar Tetap dalam Bidang Ilmu Bedah Fakultas Kedokteran Universitas Udayana

Mellanie. (2011). Theoretical basis for nursing. China: Wolters Kluwer

National Medical Policy. (2015). Hospice Care. Policy Number: NMP238. Health Net.

NCI. (2014). Coping With Advanced Cancer. NIH: USA

Next Step In Care. (2013). Family Caregiver's Guide to Hospice and Palliative Care. United Hospital Fund. www.nextstepincare.org

NHPCO. (2012). NHPCO's Facts and Figures Hospice Care in America. NHPCO: USA

NHPCO. (2013). NHPCO's Facts and Figures Hospice Care in America. NHPCO: USA

NHPCO. (2014). NHPCO's Facts and Figures Hospice Care in America. NHPCO: USA

Norman. (2008). When Skeptics Ask: A Handbook on Christian Evidences, Baker, ISBN 9780-80101498-7.

O'Callaghan. (2014). Guidelines For The Physiotherapy Management Of Motor Neuron Disease (Mnd). Mnd Guideline Development Group. Phoenix Centre, Longford

PALIATIVE AND SUPPORTIVEE INSTITUTE. (2013). Health Care Guideline Palliative Care. www.icsi.org

Pandey. (2015). Quality of Life of Patients Undergoing Cancer Treatment in B.P Koirala Memorial Cancer Hospital, 
Bharatpur, Chitwan, Nepal. American Journal of cancer Prevention, Vol. 3 No. 2, 35-44.

Polit \& Beck. (2012). Nursing research: generating and Assessing Evidence For Nursing Practice. Philadelpia: Lippincott William \& Wilkins

Ravitch \& Riggan. (2011). Reason \& Rigor: How Conceptual Frameworks guide Research. Thousand Oaks: Sage Pub

Richards \& Morse. (2013). Read me first for a user's guide to qualitative methods. $3^{\text {rd }}$ Ed. Thousand Oaks: Sage Pub

RisKesDas. (2013). Laporan Hasil Riset Kesehatan Dasar. Litbang.depkes.go.id

Robson. (2011). Real World Research, $3^{\text {rd }}$ ed. West Sussex: Wiley

Saldana. (2009). The coding manual for qualitative researcher. Thousand Oaks: Sage Pub

Simms. (2007). Palliative and Hospice care. Oxford University Press: New York

Susilo et all. (2015). Riset Kualitatif \& Aplikasi Penelitian Ilmu Keperawatan. Trans Info Media: Jakarta.

Taekyu. (2012). Comparison of Medical Expenditure According to Types of hospice Care in Patients With Terminal Cancer. American Journal of Hospice and Palliative Medicine. AM J HOSP PALLIAT CARE 30:50

Talebreza. (2014). The Hospice Referral. University of Utah School of Medicine. Salt Lake City

Teresa. (2013). Importance and Timing of End of Life care Discussion Among Gynecologic Oncology Patients. American Journal of Hospice and palliative Medicine. AM J HOSP PALLIAT CARE 30:59.
Trinh. (2014). Effects of supervised exercise on Motivational Outcomes in Breast Cancer Survivors at 5-years Follow-Up. European Journal of Oncology Nursing. Elsevier 557-563.

UPMC. (2013). The Difference Between Palliative And Hospice Care.PSI: USA

WHO. (2013). WHOLibrary Cataloguing-inPublication Data.www.who.int.

WHO. (2015). WHO Library Cataloguing-inPublication Data.www.who.int

Williams. (2013). Introduction to Probability and Statistics. Duxbury Press. England

Williams \& Hopper. (2007). Medical Of Nursing. Elsevier. Missauri. USA

Williams \& Hopper. (2015). Understanding Medical Surgical Nursing. Philadelphia: F.A. Davis.

Wira. (2012). Hubungan Kualitas Hidup Dengan Kebutuhan Perawatan Paliatif Pada Pasien Kanker Di Rsup Sanglah Denpasar. Proquest

Witjaksono. (2013).Artikel Hospis: Rumah bagi Pasien Stadium Terminal.CDK-210/ vol. 40 no. 11.Jakarta

Zahrani et all. (2012). Pattern of Cancer Deaths in a Saudi Tertiary Care Hospital. American Journal of Hospice and palliative Medicine. AM J HOSP PALLIAT CARE 30:21.

Zanartu. (2012). Prognostication I: Improving Accuracy to Support Care and Hospice Access. Institute for Innovation In Palliative care. USA

Zeinah. (2012). Middle East Experience in Palliative Care. American Journal of Hospice and Palliative Medicine. AM J HOSP PALLIAT CARE 30:94. 